\title{
Effects of match period and playing position on the individual and collective dynamics in professional soccer: a case study
}

\section{Efeitos do tempo e posição de jogo nas dinâmicas individuais e coletivas no futebol profissional: um estudo de caso}

\author{
Gibson Moreira Praça ${ }^{\top}$ \\ (D) https://orcid.org/0000-0001-9971-7308 \\ André Gustavo Pereira de Andrade ${ }^{1}$ \\ (D) https://orcid.org/0000-0003-3406-4558 \\ Sarah da Glória Teles Bredt ${ }^{1}$ \\ (1D) https://orcid.org/0000-0003-1014-9434 \\ Pedro Emilio Drumond Moreira ${ }^{1}$ \\ (D) https://orcid.org/0000-0003-1753-3391 \\ Gustavo De Conti Teixeira Costa 2 \\ (D) https://orcid.org/0000-0003-0911-8753 \\ Henrique de Oliveira Castro 3,4 \\ (D) https://orcid.org/0000-0002-0545-164X \\ Rodrigo Aquino ${ }^{5}$ \\ (D) https://orcid.org/0000-0002-4885-7316
}

\begin{abstract}
This study aimed to compare the width, the length, the length per width ratio, and the stretch index between the first and the second halves in official soccer matches, and to compare the spatial exploration index between players from different positions. Seventeen professional soccer players from a Brazilian club participated in the study and were monitored during six official matches by a GPS device. Collective positional data were compared between the two halves using a paired t-test, while the spatial exploration index was compared between the playing positions and within the halves by a mixed two-way ANOVA. The results revealed no differences between the two halves for the collective variables. The highest values of spatial exploration index were reported for central midfielders and wing forwards. We conclude that the tactical behavior of professional soccer players is position-dependent, and midfielders are the most exploratory players on the pitch.
\end{abstract}

Key words: Exercise; Soccer; Sports; Task performance and analysis.

Resumo - Este estudo comparou a largura, profundidade, razão entre profundidade largura e o indice de alongamento entre o primeiro e o segundo tempo de jogos oficiais de futebol, $e$ o indice de exploração espacial entre jogadores de diferentes posiçöes. Dezessete jogadores profissionais de futebol de um clube brasileiro participaram deste estudo e foram monitorados por um equipamento de GPS durante seis partidas oficiais do campeonato regional. Utilizou-se o teste t-pareado para comparar os dados coletivos entre os tempos de jogo, e uma ANOVA mista de duas vias para comparar a exploração espacial entre jogadores de diferentes posiçôes nos dois tempos de jogo. Os resultados indicaram não haver diferença significativa nas variáveis coletivas entre os dois tempos de jogo. Maiores valores de exploração espacial foram reportados para meio-campistas e extremos. Conclui-se que o comportamento tático de jogadores profissionais é dependente da posição, e meio-campistas são os jogadores que mais exploram o campo de jogo.

Palavras-chave: Análise e desempenho de tarefas; Esporte; Exercício; Futebol.

\begin{abstract}
1 Universidade Federal de Minas Gerais. Belo Horizonte, MG. Brazil.

2 Universidade Federal Goiás.Goiânia, GO. Brazil.
\end{abstract}

3 Instituto de Educação Superior de Brasília. Brasília, DF. Brazil.

4 Faculdade Anhanguera de Ciências e Tecnologia de Brasília. Brasília, DF. Brazil.

5 Universidade Federal do Espírito Santo. Vitória, ES. Brazil.

Received: May 12, 2020 Accepted: August 06, 2020

How to cite this article Praça GM, Andrade AGP, Bredt SGT, Moreira PED, Costa GDCT, Castro $\mathrm{HO}$, Aquino R. Effects of match period and playing position on the individual and collective dynamics in professional soccer: a case study. Rev Bras Cineantropom Desempenho Hum 2020, 22:e74688.DOl: http://dx.doi. org/10.1590/1980-0037.2020v22e74688

Copyright: This work is licensed under a Creative Commons Attribution 4.0 International License. 


\section{INTRODUCTION}

Match analysis is a methodological approach in sports science that has been progressively growing due to the development of different technological systems, such as Global Positioning Systems (GPS) ${ }^{1}$. These micro-technologies were initially used to collect information about players' physical responses, such as the total distance covered, the distances covered at different speed zones, and accelerations ${ }^{2-4}$ during match play, according to playing position. Three hundred top-class outfield soccer players were monitored during 20 Spanish Premier League and 10 Champions League games using a computerized match analysis system (Amisco Pro, Nice, France. However, players' displacements over the pitch reveal their tactical intentions to solve the emerging problems of match ${ }^{5}$ a growing number of studies now analyse tactical behaviours in football based on the collective movements of team players. Objective: The aim of this systematic review is to provide a summary of empirical research on collective tactical behaviours in football, with a particular focus on organising the methods used and their key findings. Methods: A systematic search of relevant English-language articles was performed on one database (Web of Science Core Collection. Recent studies have assessed tactical behavior using the positional data provided by the GPS devices ${ }^{4,6}$ width, centroid distance (average point between teammates. This cartesian coordinates ${ }^{7}$ organizes the acute effects of the most common task conditions, and describes the common methodologies used in previous studies. Following the preferred reporting items for systematic reviews and meta-analyses (PRISMA are easily obtained by most of the GPS devices and can be used to detect movement patterns and teams' and players' performances during a match. This type of analysis can be conducted to obtain variables related to collective behavior, such as team's length ${ }^{8}$, width ${ }^{8}$, length per width ratio (LPWRatio) ${ }^{8}$, stretch index ${ }^{9}$ the present study examined the multi-level nature of the game constraints that afford the action of a drive in basketball (dyadic attacker-defender versus inter-team relationships, and approximate entropy $(\mathrm{ApEn})^{10}$; and individual behavior, such as players' average position on the pitch (centroid) and spatial exploration index (SEI ${ }^{11}$ technical and physiological variations induced through the use of different soccer game formats have been widely discussed. However, the coaching justification for the specific use of certain game formats based on individual and collective spatial awareness is unclear. As a result, the purpose of this study was to analyze 11 versus 11 game formats conducted across two pitch sizes (half-size: $54 \mathrm{~m} \times 68 \mathrm{~m}$ vs full-size: $108 \mathrm{~m} \times 68 \mathrm{~m}$.

Previous studies found differences between the first and the second game halves for many technical, tactical, and physical variables ${ }^{12}$ Finnemore, and Sell it presents the evolution of the Union of European Football Associations (UEFA. Winning teams were reported to score more goals in the second half than in the first ${ }^{12}$ Finnemore, and Sell it presents the evolution of the Union of European Football Associations (UEFA, which 
could denote a less stable organization in the second half. On the other hand, other studies have reported stable collective positional dynamics when comparing the two halves ${ }^{13}$ allowing understanding the multilevel organization of tactical behaviors, and to determine the similarity of patterns performed by different groups of teammates during the first and second halves. Positional data from 20 professional male soccer players from the same team were collected using high frequency global positioning systems $(5 \mathrm{~Hz}$. Nevertheless, in both studies mentioned above, only one official match was evaluated, which might explain the high variability in the outcomes. Although divergent results have been recently presented regarding the influence of fatigue on match performance, it may contribute to decreasing performance throughout a match ${ }^{14}$. For this reason, the team's strategy and the level of compactness may change throughout the match, which could lead to increased values of length, width, and stretch index. However, to the best of our knowledge, the collective responses in the two-game halves have not been compared in official soccer matches.

Players' behavior in a match is influenced by their playing position. Central midfielders (CM) cover the highest distance in official matches ${ }^{2,15}$ and are considered the most prominent players in building attacks ${ }^{16,17}$. For these reasons, we expect that CMs are demanded to explore the pitch in both the offensive and defensive phases, presenting a higher spatial exploration index. This hypothesis, however, has not been tested. Besides, situational variables such as the momentary score are reported to influence players' behavior in different manners, according to playing position. Specifically, central defenders presented lower prominence in winning than in losing status, while wing forwards and center-forwards presented higher prominence in winning status ${ }^{18}$. These data indicate that relevant information may be obtained by analyzing different match situations, which could be missed when only the whole match is considered. Besides, it has been shown that technical differences between playing positions become less evident in the second half of the match ${ }^{19}$, suggesting a less planned behavior by the end of the match, possibly due to situational constraints (e.g., fatigue or momentary score). For this reason, we expect that players' SEI will be higher in the second half of the match, which has not been tested.

Based on the abovementioned rationale, the aim of this study was twofold:1) to compare the collective positional variables between the first and the second halves of official matches played by a Brazilian professional club and 2) to compare the SEI between playing positions in both halves of the game. We expect this study to provide a better comprehension of the team and individual performances in professional soccer.

\section{METHOD}

\section{Participants}

The sample of this study was non-probabilistically, determined by convenience. Six official matches played by 17 professional soccer players $(25.24$ 
\pm 5.48 years, $74.68 \pm 6.23 \mathrm{~kg}$, body fat $10.89 \pm 1.24 \%$ ) were analyzed. All players belonged to the same team, which participated in the first division of the regional competition of the state of Minas Gerais. Each player was classified by the coaching staff as a central defender (CD), fullback $(\mathrm{FB})$, central midfielder $(\mathrm{CM})$, wing forward $(\mathrm{WF})$, or center-forward $(\mathrm{CF})$. When a player was assigned to more than one playing position, the heatmap of each match was used to determine the major role of the player (see figure 1). Data were included in the analysis when they followed two criteria: (i) Only data regarding players' participation in the whole match; (ii) There were no significant changes in the playing position within the match. Data from substitute players were included only when they acted in the same position of the replaced player. During all the matches, the team played in a 1-4-2-3-1 tactical formation, reducing the variability in the positional responses. This study was approved by the local ethics committee (CAAE 19596019.9.0000.5149).

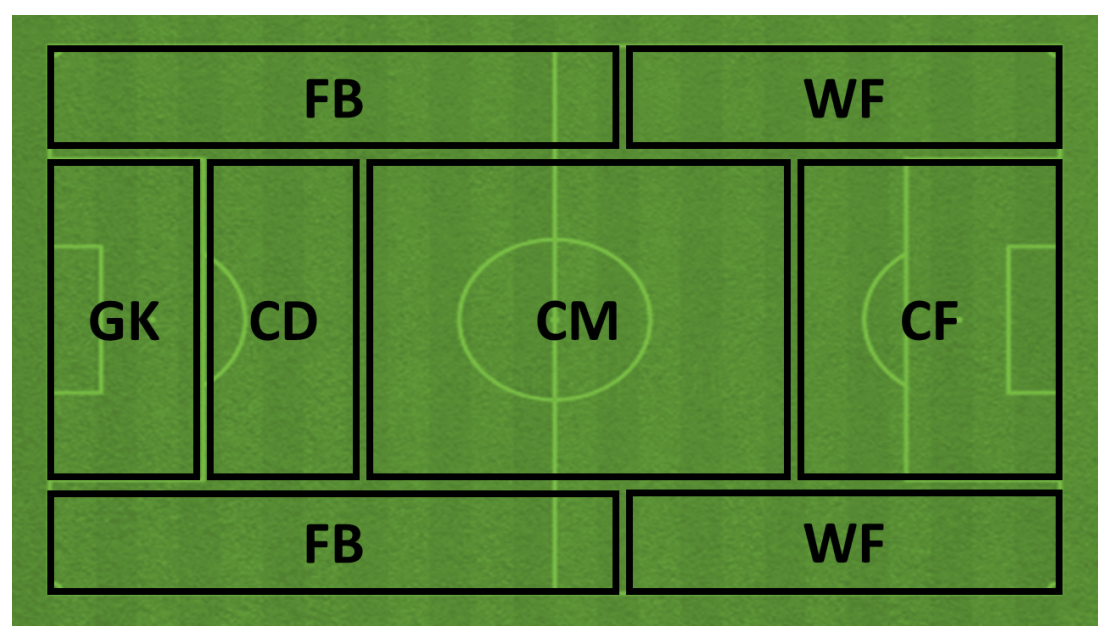

Figure 1. Classification of playing positions according to the area they mainly occupy in the field. Notes: GK: Goalkeeper; CD: Central Defender; FB: Fullback; CM: Central Midfielder; WF: Wide Forward; CF: Center-forward.18

\section{Design and Procedures}

Data collection occurred during the official matches of the regional championship of 2019. This competition comprised six matches, three home and three away, against three opponents within a group. For this reason, the influence of the level of opposition ${ }^{20}$ and match-venue ${ }^{21}$ was standardized, reducing the influence of situational variables on the results.

During the matches, the players carried GPS devices (Polar ${ }^{\circledR}$, Team Pro, Kempele, Finland) within a chest strap. The GPS was turned on at the beginning of the warm-up to facilitate satellite identification and reduce missing data. After the match, the data was downloaded and analyzed using the Polar Team Pro online software. We synchronized the devices with the online system by positioning them into a dock station connected to a tablet (Ipad $6^{\text {th }}$ generation - Apple Inc. - California, USA). We added the match time intervals within the Polar Team Pro online system to obtain the data. 


\section{Measures}

Players' positional data were recorded using $10 \mathrm{~Hz}$ GPS devices with an embedded $200 \mathrm{~Hz}$ accelerometer (Polar ${ }^{\circledR}$, Team Pro, Kempele, Finland). The reliability of $10 \mathrm{~Hz}$ GPS devices for analyzing sport-based movements has been reported to be acceptable ${ }^{22}$. The positional data were processed in MATLAB 2010a (The MathWorks Inc., Natick, MA, USA). Latitude and longitude data of each player were synchronized and converted into meters, using the Universal Transverse Mercator (UTM) coordinate system and a MATLAB script ${ }^{23}$. The data were smoothed using a second-order 5 $\mathrm{Hz}$ Butterworth low pass filter. After converting the positional data into meters, a rotation matrix was calculated for each match with the positions of the field vertices aligning the length of the playing field with the $\mathrm{x}$-axis and the width with the $y$-axis. Then, the rotation matrix was applied to players' positional data for alignment with the playing field referential ${ }^{20}$. We calculated the following variables: the width and length, determined by the distance between the furthest players in length, and its rightmost and leftmost players in the width, respectively ${ }^{4}$; the length per width ratio $(\mathrm{LpWratio})^{8}$; the stretch index, which is the mean deviation of each player from the team geometrical center ${ }^{9}$ the present study examined the multilevel nature of the game constraints that afford the action of a drive in basketball (dyadic attacker-defender versus inter-team relationships; and the spatial exploration index (SEI), defined as the average difference between a player's average position and its actual position at each moment of the match $^{4}$. From a practical perspective, the LpWratio indicates the preferential displacement axis of a team and can be used to infer whether the team uses a more flattered (i.e., higher values of length than width, resulting in a value higher than 1) or stretched (i.e., higher width than length, resulting in a value lower than 1) spatial positioning. The stretch index indicates the team's dispersion, and larger values indicate a reduced compactness ${ }^{4}$. The SEI indicates how exploratory was the player's behavior. Higher SEI values indicate more exploratory movements, while lower values indicate more positional behavior.

\section{Statistical Analysis}

Initially, the assumptions of normality (Shapiro-Wilk's test) and homoscedasticity (Levene's test) were tested. The variables width and LPWRatio presented significant deviations from normality and Wilcoxon's test was used to compare them between game halves. The other collective variables (length and stretch index) were compared using a paired t-test. To compare the SEI between playing positions within halves, a mixed two-way ANOVA was conducted. Pairwise comparisons were made using Tukey's post hoc. In all cases, the level of significance was set at 5\%, and all analyses were conducted using the software SPSS 19.0. Cohen's d effect sizes were calculated for each pairwise comparison using the software GPower 3.17, and classified as small (0.3), medium (0.5), or large $(0.8)^{24}$. 


\section{RESULTS}

Table 1 presents the comparisons between the two-game halves for the collective measures. No significant differences were found and only the LPWRatio presented a medium-to-large effect size.

Table 1. Comparison of the collective variables between game halves in professional soccer players.

\begin{tabular}{lcccc}
\hline & First Half & Second Half & p-value & Effect Size \\
\hline Length $(\mathrm{m})$ & $33.9(3.02)$ & $35.3(4.21)$ & 0.116 & 0.372 \\
Width $(\mathrm{m})$ & $38.5(3.48)$ & $39.2(4.57)$ & 0.600 & 0.169 \\
LPWRatio (AU) & $0.88(0.02)$ & $0.90(0.03)$ & 0.075 & 0.755 \\
Stretch Index $(\mathrm{m})$ & $24.4(1.70)$ & $24.7(0.89)$ & 0.678 & 0.203 \\
\hline
\end{tabular}

Figure 2 shows the SEI presented by the different playing positions within the two halves. No interaction effect was found between the game halves and playing positions $(\mathrm{p}=0.694)$. There were no significant differences between game halves $(p=0.071)$. However, a significant effect of playing a position was found $(\mathrm{p}=0.003)$. Pairwise comparisons revealed that central midfielders presented a higher SEI than fullbacks (d=0.891; large effect), central defenders $(\mathrm{d}=0.942$; large effect), and center-forwards $(\mathrm{d}=0.748$; medium-to-large effect). Besides, wing forwards presented a higher SEI than central defenders $(\mathrm{d}=0.838$; large effect).

\section{DISCUSSION}

This study aimed to compare the collective positional data of official soccer matches between the first and the second game halves. The results indicated no differences between the halves, which is contrary to our hypothesis. We also aimed to compare the SEI between playing positions within the halves. No differences between the halves were found, while specificities regarding the playing positions were noticed with large effect sizes. In this case, central midfielders and wing forwards presented the highest spatial exploration index, corroborating our hypothesis.

We hypothesized that players' ability to keep stable tactical structures would be reduced throughout the match with lower values in the second game half. However, our results showed no significant differences between the halves for the collective positional variables. There are two main possible explanations for this result. Congested fixtures were reported to increase the physical ${ }^{25}$ within theU13 and U14 age groups. One 7-a-side game (goalkeeper included and psychological ${ }^{26}$ loads imposed on players, which could lead to a non-optimal physical status at the beginning of each match and increase the differences between halves. Nevertheless, the regional state championship has only six matches over the season, played once a week, allowing an almost-complete recovery between matches. Secondly, as a club strategy, seventeen outfield players started the six matches. This rotation in the match starters may have reduced the impact of fatigue on 


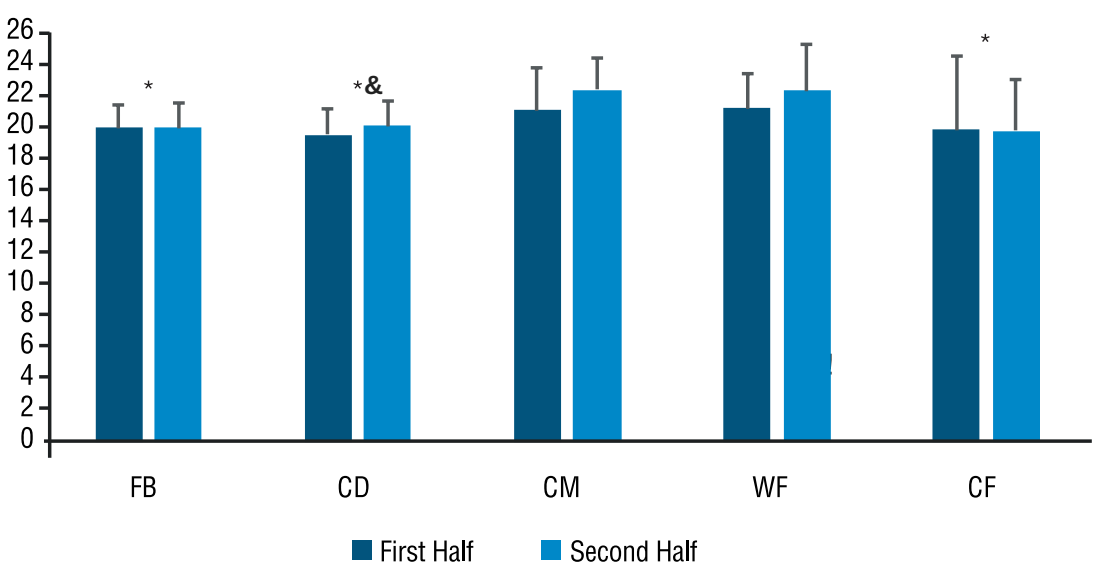

Figure 2. Comparisons of spatial exploration index (meters) between playing positions and game halves in professional soccer players.

Notes: FB: fullback; CD: central defender; CM: central midfielder; WF: wing forward; CF: centerforward; *: lower than central midfielder; \&: lower than wing forward.

players' physical responses. We recommend futures studies to investigate longer championships, maybe those played in congested fixtures.

Previous research has shown that midfielders play a major role in organizing the team's offensive phase $\mathrm{e}^{16-18}$, acting as bridges between the defensive and the offensive pitches. Additionally, midfielders usually have a box-to-box function ${ }^{27}$ resulting in 1569 passes analyzed and converted in a weighted adjacency matrix. Using that matrix, macro network measures and network centralities were calculated. Moreover, semi-structured interviews were carried out with two members of the technical staff (head coach and performance analyst, which may explain the higher values of spatial exploration index reported in this study. We also believe that the 1-4-2-3-1 playing formation adopted by the team during the whole championship increased exploratory behavior of $\mathrm{CM}$ since there are usually few available players on the midfield in comparison to other tactical formations (e.g., 1-4-4-2). However, high exploratory behavior may hinder team stability during the match. For this reason, coaches should constantly evaluate players' responses to adjust the team strategy and promote adequate training programs to increase team stability and tactical performance. Thus, future studies are recommended to test whether team formation may influence spatial exploration differently according to playing positions.

This is the first study to examine the collective and individual positional demands in official soccer matches according to playing positions and game halves. However, some limitations must be highlighted. Although the sample in the present study is higher than in previous ones, only one team and six matches were analyzed. This reduces the external validity of the results and points out the necessity of future studies to investigate larger samples. Also, some intervenient variables were not controlled, such as the effective playing time, environmental conditions, and the pitch size (which is not standardized in sub-elite competitions in Brazil), which may have biased the results. 


\section{CONCLUSION}

We conclude that positional spatial exploration is position-dependent in professional soccer, with midfielders being the most exploratory players. Besides, collective tactical variables are not different between game halves. The data presented in this study have a practical value for coaches and practitioners for the creation of representative task designs during the training sessions (e.g., to stimulate midfielders to adopt a highly exploratory behavior during the training). However, further studies with different teams and tournaments must be performed to generalize the results.

\section{Acknowledgments}

We thank Coimbra Sports for participating in the study and to Polar Brazil for supporting data collection.

\section{COMPLIANCE WITH ETHICAL STANDARDS}

\section{Funding}

We thank to FAPEMIG, CAPES, and Pró-reitoria de Pesquisa of Universidade Federal de Minas Gerais for financial support.

\section{Ethical approval}

Ethical approval was obtained from the Institutional Ethics Board of the Universidade Federal de Minas Gerais (CAAE: 64639417.0.0000.5149). The research protocol was built following the standards established by the Declaration of Helsinki. Comité de Ética e Pesquisa - CEP - UFMG.

\section{Conflict of interest statement}

The authors have no conflict of interest to declare.

\section{Author Contributions}

Conception and design of the experiment: GMP, AGPA, SGTB, PEDM. Realization of the experiments: GFB, PEDM, GCTC, HOC. Data analysis: GFB, AGPA, SGTB, RA. Contribution with reagents/research materials/analysis tools: GMP, AGPA, SGTB, PEDM, GCTC, HOC, RA. Article Writing: GMP, AGPA, SGTB, PEDM, GCTC, HOC, RA. All authors read and approved the final version of the manuscript.

\section{REFERENCES}

1. Sarmento H, Clemente FM, Araújo D, Davids K, McRobert A, Figueiredo A. What Performance Analysts Need to Know About Research Trends in Association Football (2012-2016): A Systematic Review. Sport Med 2018;48(4):799-836.

2. Di Salvo V, Baron R, Tschan H, Calderon Montero FJ, Bachl N, Pigozzi F. Performance characteristics according to playing position in elite soccer. Int J Sport Med 2007;28(3):222-7.

3. Bredt SGT, Praça GM, Figueiredo LS, Paula LV, Silva PCR, Andrade AGP, et al. Reliability of physical, physiological and tactical measures in small-sided soccer games with numerical equality and numerical superiority. Rev Bras Cineantropom Desempenho Hum 2016;18(5):602-10. 
4. Clemente FM, Bernardo Sequeiros J, Correia AFPP, Silva FGM, Martins FML. Computational metrics for soccer analysis: connecting the dots. Cham: Springer; 2018.

5. Low B, Coutinho D, Gonçalves B, Rein R, Memmert D, Sampaio J. A Systematic Review of Collective Tactical Behaviours in Football Using Positional Data. Sport Med 2020;50:343-85.

6. Praça GM, Folgado H, Andrade AGP, Greco PJ. Influence of additional players on collective tactical behavior in small-sided soccer games. Rev Bras Cineantropom Desempenho Hum 2016;18(1):62-71

7. Clemente FM, Afonso J, Castillo D, Arcos AL, Silva AF, Sarmento H. The effects of small-sided soccer games on tactical behavior and collective dynamics: A systematic review. Chaos Solitons Fractals 2020;134:109710.

8. Folgado H, Lemmink KAPM, Frencken W, Sampaio J. Length, width and centroid distance as measures of teams tactical performance in youth football. Eur J Sport Sci 2014;14(SUPPL.1):S487-92.

9. Bourbousson J, Deschamps T, Travassos B. From Players to Teams: Towards a Multi-Level Approach of Game Constraints in Team Sports. Int J Sports Sci Coach 2014;9(6):1393-406.

10. Yentes JM, Hunt N, Schmid KK, Kaipust JP, McGrath D, Stergiou N. The appropriate use of approximate entropy and sample entropy with short data sets. Ann Biomed Eng 2013;41(2):349-65.

11. Clemente FM, Owen A, Serra-Olivares J, Correia A, Bernardo Sequeiros J, Silva FG, et al. The effects of large-sided soccer training games and pitch size manipulation on time-motion profile, spatial exploration and surface area: Tactical opportunities. Proc Inst Mech Eng Part P J Sport Eng Technol 2018;232(2):160-5.

12. Muhamad S, Norasrudin S, Rahmat A. Differences in Goal Scoring and Passing Sequences between Winning and Losing Team in UEFA-EURO Championship 2012. Int J Humanit Soc Sci 2013;7(2):332-7.

13. Ric A, Torrents C, Gonçalves B, Sampaio J, Hristovski R. Soft-assembled multilevel dynamics of tactical behaviors in soccer. Front Psychol 2016;7:1513.

14. Carling C, Bradley P, McCall A, Dupont G. Match-to-match variability in highspeed running activity in a professional soccer team. J Sports Sci 2016;34(24):2215-23.

15. Rivilla-García J, Calvo LC, Jiménez-Rubio S, Paredes-Hernández V, Muñoz A, van den Tillaar $\mathrm{R}$, et al. Characteristics of very high intensity runs of soccer players in relation to their playing position and playing half in the 2013-14 Spanish La Liga season. J Hum Kinet 2019;66:213-22.

16. Clemente FM, Martins FML, Kalamaras D, Wong DP, Mendes RS. Midfielder as the prominent participant in the building attack : A network analysis of national teams in FIFA World Cup 2014. Int J Perform Anal Sport 2015;15(2):704-22.

17. Aquino R, Carling C, Palucci Vieira LH, Martins G, Jabor G, Machado J, et al. Influence of Situational Variables, Team Formation, and Playing Position on Match Running Performance and Social Network Analysis in Brazilian Professional Soccer Players. J Strength Cond Res 2020;34(3):808-17.

18. Praça GM, Lima BB, Bredt SGT, Sousa RB, Clemente FM, Andrade AGAGP de. Influence of Match Status on Players' Prominence and Teams' Network Properties During 2018 FIFA World Cup. Front Psychol 2019;10:695.

19. Ortega J, Evangelio C, Clemente F, Martins F, González-Víllora S. Analysis of Physiological, Technical, and Tactical Analysis during a Friendly Football Match of Elite U19. Sports 2016;4(2):35.

20. Folgado H, Duarte R, Fernandes O, Sampaio J. Competing with Lower Level Opponents Decreases Intra-Team Movement Synchronization and Time-Motion Demands during Pre-Season Soccer Matches. Plos One 2014;9(5):e97145.

21. García-Rubio J, Gómez MÁ, Lago-Peñas C, Ibáñez JS. Effect of match venue, scoring first and quality of opposition on match outcome in the UEFA Champions League. Int J Perform Anal Sport 2015;15(2):527-39.

22. Köklü Y, Arslan Y, Alemdaroğlu U, Duffield R. Accuracy and reliability of SPI ProX global positioning system devices for measuring movement demands of team 
sports. J Sport Med Phys Fit 2015;55(5):471-7.

23. Palacios R. deg2utm. MATLAB Central File Exchange. Downloaded at http:// www.mathworks.com/matlabcentral/fileexchange/10915. Accessed: October 20 2012. 2006.

24. Cohen J. Statistical Power Analysis for the Behavioral Sciences. 2nd ed. Hillsdale, NJ: Lawrence Erlbaum Associates Publishers; 1988.

25. Brito J, Krustrup P, Rebelo ANC, Dellal A, Owen AL, Wong DP, et al. Physiological responses, fatigue and perception of female soccer players in small-sided games with different pitch size and sport surfaces. J Strength Cond Res 2018;10(1):229-35.

26. Coutts AJ. Fatigue in football: it's not a brainless task! J Sport Sci 2016;34(14):1296.

27. Sarmento H, Clemente FM, Gonçalves E, Harper LD, Dias D, Figueiredo A. Analysis of the offensive process of AS Monaco professional soccer team: A mixedmethod approach. Chaos Solitons Fractals 2020;133:109676.

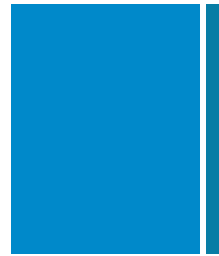

Corresponding author

Gibson Moreira Praça

Universidade Federal de Minas Gerais

Escola de Educação Física, Fisioterapia e Terapia Ocupacional

Departamento de Esportes

Av. Presidente Antônio Carlos, 6627. Campus Pampulha. CEP 31270-901.

Belo Horizonte, Minas Gerais, Brazil.

E-mail: gibson_moreira@yahoo.com.br 